\title{
Urothelial bladder cancer progression: lessons learned from the bench
}

\author{
Julieta P. Afonso ${ }^{1,2}$, Rui Freitas ${ }^{3}$, Francisco Lobo ${ }^{3}$, António Morais ${ }^{3}$, Jorge Oliveira ${ }^{3}$, Teresina Amaro ${ }^{4}$, \\ Rui M. Reis ${ }^{1,2,5}$, Fátima M. Baltazar ${ }^{1,2}$, Adhemar Longatto-Filho ${ }^{1,2,5,6}$, Lúcio L. Santos ${ }^{7,8}$ \\ ${ }^{1}$ Life and Health Sciences Research Institute (ICVS), School of Health Sciences, University of Minho, Campus de Gualtar, $4710-057$ Braga, Portugal. \\ ${ }^{2}$ ICVS/3B's-PT Government Associate Laboratory, 4806-909 Braga/Guimarães, Portugal. \\ ${ }^{3}$ Department of Urology, Portuguese Institute of Oncology, Rua Dr. António Bernardino de Almeida, 4200-072 Porto, Portugal. \\ ${ }^{4}$ Experimental Pathology and Therapeutics Research Center, Portuguese Institute of Oncology, Rua Dr. António Bernardino de Almeida, \\ 4200-072 Porto, Portugal. \\ ${ }^{5}$ Molecular Oncology Research Center, Barretos Cancer Hospital, CEP 14784-400 Barretos, São Paulo, Brazil. \\ ${ }^{6}$ Laboratory of Medical Investigation (LIM 14), Faculty of Medicine, São Paulo State University, CEP 01246-000, São Paulo, Brazil. \\ ${ }^{7}$ Department of Surgical Oncology, Portuguese Institute of Oncology, Rua Dr. António Bernardino de Almeida, 4200-072 Porto, Portugal. \\ ${ }^{8}$ Faculty of Health Sciences, University Fernando Pessoa, Rua Carlos da Maia, 4200-150 Porto, Portugal.
}

Correspondence to: Dr. Julieta P. Afonso, Life and Health Sciences Research Institute (ICVS), School of Health Sciences, University of Minho, Campus de Gualtar, 4710-057 Braga, Portugal. E-mail: julietaafonso@ecsaude.uminho.pt

\section{A B S T R A C T}

Urothelial bladder carcinoma (UBC) is an intricate malignancy with a variable natural history and clinical behavior. Despite developments in diagnosis/prognosis refinement and treatment modalities, the recurrence rate is high, and progression from non-muscle to muscle invasive UBC commonly leads to metastasis. Moreover, patients with muscle-invasive or extra-vesical disease often fail the standard chemotherapy treatment, and overall survival rates are poor. Thus, UBC remains a challenge in the oncology field, representing an ideal candidate for research on biomarkers that could identify patients at increased risk of recurrence, progression, and chemo-refractoriness. However, progress toward personalized medicine has been hampered by the unique genetic complexity of UBC. Recent genome-wide expression and sequencing studies have brought new insights into its molecular features, pathogenesis and clinical diversity, revealing a landscape where classical pathology is intersected by the novel and heterogeneous molecular groups. Hence, it seems plausible to postulate that only an integrated signature of prognostic/predictive biomarkers inherent in different cancer hallmarks will reach clinical validation. In this review, we have summarized ours and others' research into novel putative biomarkers of progression and chemoresistance that encompass several hallmarks of cancer: tumor neovascularization, invasion and metastasis, and energy metabolism reprogramming of the tumor microenvironment.

Key words: CD147, lymphovascular invasion, mammalian target of rapamycin, monocarboxylate transporters, progression, Raf kinase inhibitor protein, scoring system, urothelial bladder cancer

\section{Introduction}

The urothelium, one of the slowest cycling epithelia in the human body, ${ }^{[1]}$ is constantly exposed to a variety of potential carcinogens that can stagnate in urine for a few hours before urination. For that reason, the bladder is a particularly high-risk organ for cancer development, and incidence and mortality from bladder cancer represent an important public health problem. An estimated 429,000 new cases of bladder cancer and 165,000 deaths occurred in 2012, worldwide. It was the 9th most common cancer for both sexes combined (4th in men, 15th in women). Sixty percent of cases occurred in more developed regions of the world (Europe, North America, North Africa). ${ }^{[2]}$ In these regions, more than $90 \%$ of all bladder tumors

\begin{tabular}{|l|l|}
\hline \multicolumn{2}{|c|}{ Access this article online } \\
\hline Quick Response Code: & Website: \\
\hline & www.jcmtjournal.com \\
\cline { 2 - 2 } & \\
\hline
\end{tabular}

originate from transitional cells of the urothelium, while approximately $5 \%$ and $2 \%$ are squamous and glandular variants, respectively, while the remainder comprises other rare subtypes. ${ }^{[3,4]}$ The most well-established risk factors for bladder carcinogenesis are cigarette smoking and industrial exposures in the context of a number of occupational settings. ${ }^{[5]}$

Of all newly diagnosed cases of urothelial bladder carcinoma (UBC), 70-80\% arise as non-muscle invasive (NMI). These tumors, although without aggressive histopathological features, often experience recurrence, and a subgroup of high-risk lesions frequently progress to invasive forms. Conversely, $20-30 \%$ originally present as muscle invasive (MI) disease. Invasion of the muscular wall portends common progression to metastasis. Despite radical cystectomy, radiation, and/or platinum-based chemotherapy, patients often fail treatment, so the 5-year overall survival (OS) rate is $<50 \%$, mostly due to chemotherapy resistance and patient fragility. ${ }^{[4,6-9]}$ Repeated relapses, occurrence of progression, and chemoresistance make UBC the costliest cancer to treat from diagnosis to death. ${ }^{[10]}$ Thus, personalization of treatment could improve patients' 
quality of life, and reduce the burden on health care systems.

Clinical staging and histopathological parameters remain the "gold standards" for UBC diagnosis and prognostic prediction. ${ }^{[11,12]}$ However, they are not sufficient to characterize individual biological features and clinical tumor behavior. Understanding disease pathobiology could potentially add essential information to these classical criteria and contribute to more accurately predicting prognosis and refine treatment. Ideally, the clinical use of standardized prognostic and predictive biomarkers could allow the prediction of tumor recurrence through a non-invasive method, avoiding use of invasive techniques, such as cystoscopy and biopsy, which cause significant patient discomfort and add substantial costs. ${ }^{[13]}$ Furthermore, it could allow timely prediction of UBC progression, from NMI to MI disease, particularly for high grade or carcinoma in situ lesions, guiding more vigilant surveillance and refining treatment strategies. ${ }^{[14]}$ Finally, it could allow the prediction of response to conventional cytotoxic therapies typically associated with chemorefractory relapse and patient fragility. ${ }^{[15]}$

A cancer-related biomarker may be defined as a molecule produced by the tumor or by the organism in response to the tumor, measurable in sample matrices such as tissue, blood, or urine, representative of the cancerous process, and reproducible, specific, and sensitive. ${ }^{[16]}$ A reasonable number of UBC biomarkers, namely those involved in the key molecular pathways of urothelial malignization (fibroblast growth factor receptor 3 and tumor protein p53 mutations), seem to be prognostically relevant. ${ }^{[17-19]}$ Despite this, there is a substantial delay in translation into the clinic, and clinical trials with molecularly targeted agents have been few in number and largely unsuccessful. ${ }^{[20]}$ There is the need to expand biomarker research beyond the current focus on therapies directed at deregulated oncogenic or tumor suppressor pathways, and into new molecular portraits encompassing all the hallmarks of cancer. ${ }^{[21]}$ In fact, recent medium- to high-throughput gene expression profiling technologies and sequencing studies have revealed a multifactorial scenario where additional molecular alterations seem to be involved in urothelial carcinogenesis and tumor progression. ${ }^{[8]}$

\section{Biomarkers of UBC Progression: Lessons Learned from the Bench}

In the next sections, we will summarize the contributions of our group and of other authors to the research of three poorly explored biological events that overlap several cancer hallmarks and seem to influence UBC progression: occurrence of tumor neovascularization, loss of metastasis suppressor proteins, and metabolic reprogramming of the tumor microenvironment.

\section{Tumor neovascularization}

The leading cause of mortality from cancer is not the primary tumor itself, but the occurrence of metastasis from the primary tumor. ${ }^{[22,23]}$ Disease dissemination can occur by direct invasion of tissues and cavities surrounding the primary site. However, the preferential course for metastases is spread through blood or lymphatic vasculature. Moreover, several preclinical and clinical studies have highlighted the preponderance of the lymphatic vascular system over the blood vascular system with the involvement of the sentinel lymph node being a standard diagnostic and prognostic parameter. ${ }^{[24,25]}$

The occurrence of "de novo" vascularization is a crucial step in the metastatic route. In fact, the tumor neovasculature not only supports the metabolic needs of the malignant cells, but also establishes the routes for dissemination. The malignant cells overexpress various angiogenic and lymphangiogenic growth factors that alter the normal neovascularization pattern, significantly increasing blood and lymphatic vessel density (BVD and LVD, respectively). ${ }^{[26]}$ The link between neovascularization and lymphovascular invasion significantly worsens prognosis, with numerous reports on its association with risk of tumor recurrence, progression, lymph node metastasis, and distant metastasis. ${ }^{[27,28]}$ Accordingly, several preclinical models have demonstrated a significant reduction in tumor growth and tumor associated-neovasculature when the expression of angiogenic and lymphangiogenic factors was blocked. ${ }^{[29-31]}$ Anti-angiogenic/lymphangiogenic agents and targeted inhibitors, in monotherapy or in combination with standard chemotherapeutic drugs, have already reached the phase of clinical trials, and several compounds have obtained approval from the Food and Drug Administration agency. ${ }^{[32,33]}$ While these agents have shown promising therapeutic effects, substantial evidence of primary and acquired resistance has been reported. ${ }^{[34]}$ Vessel normalization, by restoring physiological perfusion and oxygenation of tumor vasculature, has recently emerged as a promising strategy to overcome resistance to certain antiangiogenic therapies. ${ }^{[35]}$

In the setting of UBC, angiogenesis has been extensively reported, with several studies, including large-scale approaches, indicating the independent prognostic value of high vascular endothelial growth factor (VEGF) levels and BVD counts. ${ }^{[36-40]}$ A number of clinical trials with anti-angiogenic agents are ongoing for UBC patients with NMI and MI disease. ${ }^{[41]}$ Reports on lymphangiogenesis, although fewer in number, also point to a significant role of lymphatic vessel formation in UBC spread. Overexpression of VEGF-C, VEGF-D, and VEGFR-3, the key players of lymphangiogenesis, has been demonstrated in several studies, associating with high LVD counts and lymph node metastasis, also predicting poor prognosis. ${ }^{[40,42-45]}$ In vitro and in vivo 
studies have shown that VEGF-C/D blockade suppresses lymphangiogenesis and lymphatic metastasis, enhancing UBC chemosensitivity. ${ }^{[46,47]}$ Therefore, there is no doubt that both blood and lymphatic vessels participate in the metastatic process. Lymphovascular invasion (LI) has been identified as an independent prognostic factor for recurrence and $\mathrm{OS}^{[48,49]} \mathrm{A}$ recent meta-analysis demonstrated that LI is an important selection criterion for early cystectomy in high-grade stage T1 UBC. ${ }^{[50]}$ Also demonstrated is that the LI status helps to stratify N0 UBC patients at increased risk of UBC recurrence and death. ${ }^{[51]}$ Regardless of these important associations, LI occurrence is not included as a standard parameter in many pathology reports, mostly due to the lack of strict diagnostic criteria. ${ }^{[52,53]}$

In our research, in $83 \mathrm{UBC}$ tissue sections, we used immunohistochemistry (IHC) (CD31 and D2-40 antibodies) to assess BVD and blood vessel invasion (BVI), and lymphatic vessel invasion (LVI), respectively [Table 1]. ${ }^{[54]}$ Regarding angiogenesis occurrence, although we observed an association between BVD and parameters of UBC aggressiveness and progression, we did not find a significant influence on prognosis. In fact, conflicting results exist, ${ }^{[38,55,56]}$ and it has been advocated that additional factors are necessary to determine the real impact of angiogenesis in UBC progression and dissemination. ${ }^{[57]}$ In accordance, BVI occurred more frequently in cases with high BVD and was identified as an independent prognostic factor for OS. The same correlation was observed between LVD and LVI, although LVI was identified as a prognostic factor only by univariate analysis. Nevertheless, high LVD was significantly associated with tumor aggressiveness. These results have been corroborated by others. ${ }^{[58,59]}$ Moreover, we observed that intratumoral lymphatic vessels seemed to cooperate actively in malignant dissemination by the presence of single-malignant cells in well-preserved vessels [Figure 1b]. Although these vessels have been described as collapsed and non-functional by others, ${ }^{[60,61]}$ in our series, there was a significant proportion of cases where vessels with visible lumina were seen; edema was not observed, which would support a more efficient lymphatic flow. Accordingly, the presence of intratumoral lymphatic vessels was correlated with parameters of UBC aggressiveness in one study, ${ }^{[62]}$ and was identified as a predictive factor of pelvic lymph node metastasis in another. ${ }^{[59]}$

Another result of our study was the validation of the use of IHC markers to separate blood and lymphatic vessels. Its usefulness was particularly important in the detection of isolated malignant cells invading lymphatic capillaries [Figure 1b]. These cells, intravased in a milieu that flows slowly and has a composition similar to interstitial fluid, have a higher survival probability when compared to the typical rigors of the blood. ${ }^{[63]}$ LVI by isolated malignant cells was significantly correlated with a poor prognosis. The same association was observed when considering BVI, but only when malignant emboli were intravased [Figure 1a]. Thus, these parameters represent potential biomarkers of progression that can guide therapeutic regimes, and their routine evaluation is recommended by us and others. ${ }^{[53,54]}$ We additionally

Table 1: Major findings of selected immunohistochemical studies on urothelial bladder cancer biomarkers

\begin{tabular}{lllll}
\hline Reference Cohort & $\boldsymbol{n}$ & Markers & Cut-off & Impact on clinicopathological parameters and survival \\
\hline [54] & 83 & BVD & $\geq 17.6$ vessels & Quantification of vessel density and identification of lymphovascular \\
& LVD $\quad \geq 8.8$ vessels & invasion significantly improved when using blood (CD31) and \\
& BVI & Malignant emboli & lymphatic (D2-40) vessel markers. High LVD associated with tumor \\
& LVI & Isolated tumor cells & aggressiveness. BVI and LVI significantly lowered DFS and OS. \\
& & BVI remained an independent prognostic factor for OS.
\end{tabular}

[75] $\quad \mathrm{RC} \quad 76 \mathrm{p}-\mathrm{mTOR} \geq 10 \%$ positive cells

p-mTOR expression decreased with increasing stage and was lost from non-tumor to tumor urothelium. T3/T4 positive cases $(n=49)$ had significant worse DFS rate.

[85] $\quad$ RC $\quad 81$ RKIP $\quad \geq 10 \%$ positive cells

RKIP expression associated with favorable clinicopathological profile. Loss of RKIP expression associated with LVI occurrence, significantly lowered DFS and OS, remaining independent prognostic factor for DFS.

[100] RC and 114 MCT1 Percentage of immunoreactive MCT1, MCT4, CD147 expressions significantly associated with TUR MCT4 cells*+intensity of staining ${ }^{\dagger} \quad$ unfavorable clinicopathological parameters and poor prognosis. In CD147 (positive score $\geq 4$ ) selected platinum treated-patients, OS was significantly lower for those with MCT1+CD147-positive tumors.

[101] RC $\quad 77$ Scoring $\geq 3$ positive parameters Model stronger in predicting prognosis than individual parameters, remaining independent prognostic factor for DFS and OS. CD147 expression added significant prognostic information to the model.

${ }^{*} 0$ : $0 \%$ of positive cells; $1:<5 \%$ of positive cells; $2: 5-50 \%$ positive cells; $3:>50 \%$ of positive cells; ${ }^{\dagger} 0$ : negative; 1 : weak; 2 : intermediate; 3 : strong; ${ }^{*}$ scoring model: includes stage, grade, BVI, LVI, CD147 overexpression. BVD: Blood vessel density; BVI: Blood vessel invasion; DFS: Disease-free survival; LVD: Lymphatic vessel density; LVI: Lymphatic vessel invasion; MCT: Monocarboxylate transporter; OS: Overall survival; p-mTOR: Phospho-mammalian target of rapamycin; RC: Radical cystectomy; RKIP: Raf kinase inhibitor protein; TUR: Transurethral resection 


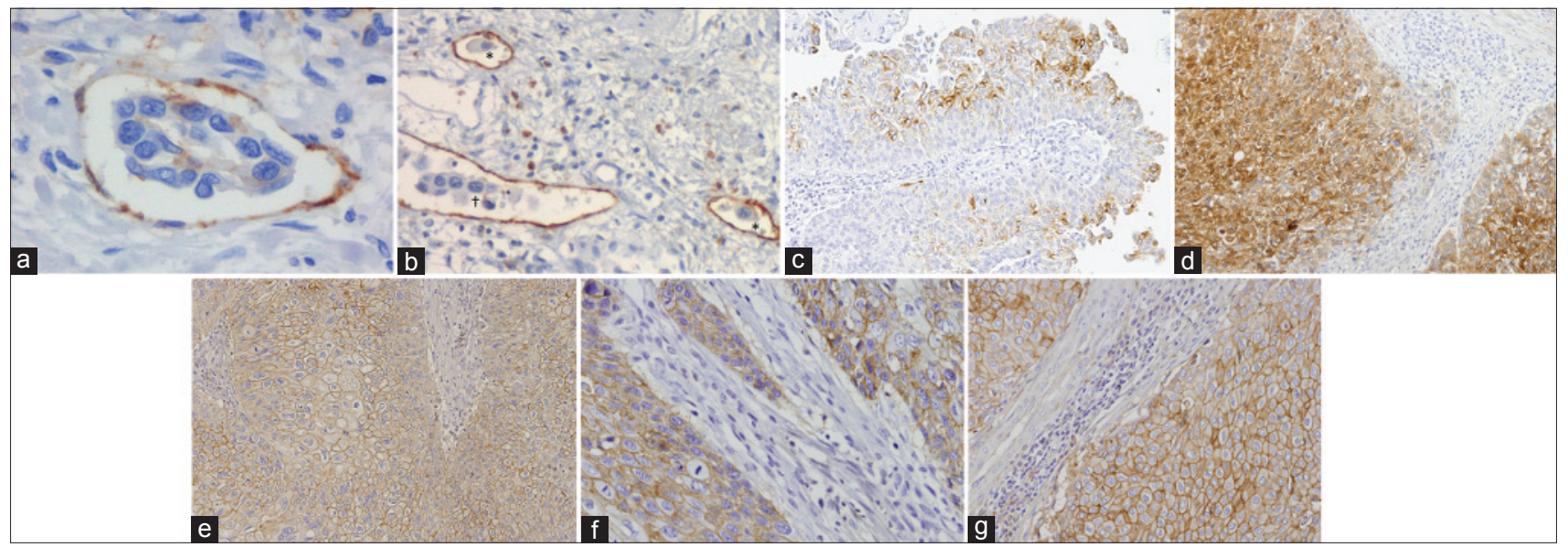

Figure 1: Representative images of immunohistochemical positive reactions for CD31, D2-40, p-mTOR, RKIP, CD147, MCT1, MCT4 in non-muscle invasive (c) and muscle invasive (a, b, d-g) urothelial bladder carcinoma (original magnifications indicated). (a) An embolus of malignant cells intravased in an intratumoral blood vessel highlighted by CD31 ( $\times 400)$; (b) isolated malignant cells $\left(^{*}\right)$ and malignant embolus $(\dagger)$ invading intratumoral lymphatic vessels highlighted by D2-40 ( $\times 200)$; (c) heterogeneous pattern of p-mTOR immunoexpression, with the intensity of staining of staining being lost from the luminal to the basal cell layers of the urothelium $(\times 100)$; (d) heterogeneous pattern of RKIP immunoexpression, with the tumor core being more intensely stained than the invasive front $(\times 100)$; (e) strong CD147 membrane immunoexpression in the inner layers of the tumor $(\times 100)$; (f) immunoexpression of MCT1 in the malignant urothelium ( $\times 200)$; $(\mathrm{g})$ immunoexpression of MCT4 in the malignant urothelium $(\times 200)$. MCT: Monocarboxylate transporter; p-mTOR: Phospho-mammalian target of rapamycin; RKIP: Raf kinase inhibitor protein

suggest specific immunostaining of blood and lymphatic vessels in histologically equivocal cases that require confirmation in order to better identify lymphovascular invasion that could have been missed during routine evaluation on HE-stained tumor sections, and to allow a more accurate discrimination between the 2 forms of lymphovascular invasion.

As above, the occurrence of angiogenesis and lymphangiogenesis as potential targets for therapeutic intervention in UBC is already under clinical testing, with several compounds targeting the most relevant neovascularization signaling pathways. ${ }^{[41,64]}$ However, as with other types of cancer, the risk of refractoriness to VEGFs/VEGFRs signaling abrogation exists. ${ }^{[65]}$ Compensatory mechanisms to VEGF blockade in UBC cell lines have been described. ${ }^{[66]}$ While these anti-neovascularization compounds have clear value, additional efforts are being undertaken in the search of alternative pathways to abrogate angiogenesis/lymphangiogenesis. The mammalian target of the rapamycin (mTOR) intracellular pathway is an important signaling mediator in hypoxia-induced angiogenesis, ${ }^{[67]}$ besides transducing activator signals for promoting cell growth. ${ }^{[68]}$ UBC pre-clinical ${ }^{[69]}$ and clinical trials, ${ }^{[70,71]}$ although few in number, ${ }^{[72]}$ have shown the anti-angiogenic effects of rapamycin analogues. Nevertheless, levels of mTOR activation in UBC tissue sections have been little explored, with controversial results being found. ${ }^{[73,74]}$ We assessed phospho-mTOR (p-mTOR) levels in a series of 76 UBC tissue sections, where blood and lymphatic vessels were also specifically stained, in order to correlate angiogenesis and lymphangiogenesis with p-mTOR expression [Table 1]. Representative tumor and non-tumor (normal-like or hyperplasic) areas were present. ${ }^{[75]}$ We did not find significant associations between clinicopathological parameters, vascular density, and p-mTOR expression. Nonetheless, p-mTOR expression [Figure 1c] decreased with increasing stage and was lost from non-tumor to tumor urothelium, particularly in muscle-invasive tumors, where immunoexpression was only observed in cell clusters. Angiogenesis was compromised in T3/T4-negative cases; conversely, the group with T3/T4-positive tumors had a quite poor outcome, as observed by others. ${ }^{[73]}$ These two patterns of expression, complete absence or presence in clusters of cells, are a possible consequence of opposing biological settings mediated by mTOR signalling. There is the need to expand the research on larger and comprehensive series of UBC patients, with molecular effectors of upstream and downstream mTOR signaling, together with reproducible IHC and molecular methodologies, and with in vivo and in vitro UBC models. This is in order to elucidate the role of the mTOR pathway in human UBC and to find more appropriate target therapeutic strategies. Accordingly, recent studies characterizing UBC genetic background revealed chromosomal alterations not seen at the same level in other types of cancers, namely, mutations of genes involved in the $\mathrm{PI} 3 \mathrm{~K} / \mathrm{AKT} / \mathrm{mTOR}$ signaling pathway. ${ }^{[76]}$

\section{Tumor metastasis}

The ability of malignant cells to leave a primary tumor and to disseminate widely is commonly agreed to be the basis for metastasis formation, the mainly cause of death from cancer. As above, angiogenesis and lymphangiogenesis are integrate parts of the metastatic process, but additional steps need to occur in order for a malignant cell or a cluster of cells colonize secondary sites. These interrelated steps involve the expression of molecular promoters 
and suppressors of metastasis. Moreover, the success of metastatic spread depends, not only on the intrinsic properties of the tumor cells, but also on host feedback. ${ }^{[7]}$

Genes inhibiting metastasis without blocking the ability of the transformed cells to develop a primary tumor are included in the group of metastasis suppressors. Obviously, loss of expression of metastasis suppressor genes is part of the metastatic genetic program, and a mandatory requisite for the success of the process. After initial scepticism following the discovery of the Nm23 gene, more than thirty protein coding/non-coding genes have been described that significantly reduce the onset of metastasis without affecting the formation of the primary tumor. Therefore, their loss occurs during cancer progression, not during transformation. ${ }^{[78,79]}$

In the UBC setting, progression of high-risk NMI tumors (high grade Ta/T1 tumors or carcinoma in situ) to muscle-invasive disease and ultimately, to extra-vesical dissemination, carries a significant risk of invasion and metastasis, despite radical surgical treatment. ${ }^{[4]}$ Inhibiting biomarkers of progression and metastasis represents an attractive therapeutic approach, but restoring the function of metastasis suppressor proteins, although poorly explored, is also appealing. In this picture, the role of the metastasis suppressor Raf kinase inhibitor protein (RKIP) in cancer has been highlighted due to its ability to modulate several intracellular signaling pathways involved in cell differentiation, cell cycle kinetics, apoptosis, epithelial to mesenchymal transition, and cell migration. ${ }^{[80,81]}$ Given its pleiotropic abilities in maintaining cellular equilibrium, RKIP downregulation is associated with metastatic events in an increasing number of solid tumors. ${ }^{[82,83]}$ Its preponderance in UBC is largely unknown. In one study, ${ }^{[84]}$ low mRNA levels were reported in NMI tumors when compared with normal urothelium. In our research, and for the first time (to the best of our knowledge), we studied 81 tumor sections from UBC patients for RKIP immunostaining [Table 1]. ${ }^{[85]}$ We observed tumors with a favorable clinicopathological profile, namely, NMI tumors where LVI was absent, with a homogeneous expression of RKIP. Conversely, LVI occurrence was associated with a heterogeneous pattern of RKIP expression, where expression intensity was lost from tumor center to invasion front [Figure 1d]. Low RKIP expression significantly impacted prognosis, remaining an independent prognostic factor for disease-free survival. As mentioned, similar associations concerning other aggressive cancer types have been previously reported. Clinically, a gradual decrease of RKIP expression was noted from benign to malignant tumors, and from those to metastastic sites. ${ }^{[82,83]}$ In the UBC setting, additional studies are needed in order to confirm our results and to expand research into therapeutic strategies that can potentially restore RKIP functionality. Besides acting as a biomarker of progression to metastatic disease, the potential role of RKIP as a predictive biomarker has also been proposed, since its expression may mediate apoptosis induced by chemotherapeutic regimes. ${ }^{[66,87]}$

\section{Tumor metabolic reprogramming}

Cancer is not only a complex genetic disease, but also a disease of deregulated bioenergetic metabolism. Elevated glycolytic rates are a common trait of malignancy. ${ }^{[88]}$ Warburg was the first to describe the metabolic switch, known as "The Warburg Effect," whereby a tumor cell avidly consumes glucose and reprograms its metabolism, producing large amounts of lactate, even under aerobic conditions. ${ }^{[89]}$ Lactate is the main source of microenvironmental acidosis in tumors, contributing to an acid-resistant phenotype that supports increased migration and invasion abilities of cancer cells. ${ }^{[90-92]}$ Its dependence on monocarboxylate transporters (MCTs) for transport across the plasma membrane directly implicates MCTs in tumor behavior.

Monocarboxylate transporters belong to the SLC16 gene family, comprising 14 members, of which MCTs 1-4, the proton-linked MCTs, mediate influx/efflux of monocarboxylates across the plasma membrane. MCT1 and MCT4 are the best characterized MCTs in human tissue, with MCT1 having ubiquitous distribution and MCT4 being present in highly glycolytic tissues. ${ }^{[93]}$ The proper expression of MCTs at the plasma membrane depends on their interaction with CD147, ${ }^{[94]}$ a cell surface glycoprotein implicated in extracellular matrix remodeling, angiogenesis, migration, and invasion and related to chemoresistance-promoting events. ${ }^{[5]}$ CD147 and MCTs overexpressions have been described in several cancers, associated with poor clinicopathological and survival parameters. ${ }^{[95,96]}$ Some in vitro models have demonstrated that CD147 downregulation sensitizes malignant cells to platinum-based therapy. ${ }^{[97-99]}$ Therefore, metabolism-related cellular pathways involved in malignancy represent potential areas of therapeutic intervention.

Biological mechanisms that reprogram cellular energetics in the setting of UBC are poorly characterized. Thus, we investigated, in a series of tumor tissue sections from 114 UBC patients, a panel of three metabolism-involved molecules [Table 1]. ${ }^{[100]}$ The central protein seemed to be CD147. We had previously demonstrated the prognostic impact of its overexpression in UBC when we developed a model of UBC aggressiveness $(n=77)$ that included classical clinicopathological (stage and grade) and biological parameters (lymphovascular invasion ${ }^{[54]}$ and CD147 expression). ${ }^{[101]}$ In fact, this scoring system separated a low aggressive from the high aggressive group, remaining as an independent prognostic factor for disease-free and OS. In the group of highly aggressive tumors, CD147 positivity was $87 \%$, clearly adding prognostic information to the model [Table 1]. Thus, we decided to re-evaluate this glycoprotein in a larger series, exploring its crosstalk with MCTs and possible role in 
chemoresistance. ${ }^{[100]}$ Significant associations were found among the biomarkers, which support the chaperone function of CD147, as corroborated by others. ${ }^{[94]} \mathrm{We}$ also observed that CD147, MCT1, and MCT4 were upregulated [Figure 1e-g], being significantly associated with a poor clinicopathological profile, namely, advancing stage, grade, type of lesion, and occurrence of LVI. Moreover, MCT1 and CD147 overexpressions were associated with poor prognosis, particularly in cases that were positive for both biomarkers. Interestingly, when we selected patients who received platinum-based chemotherapy, the prognosis was significantly worse for those with MCT1- and CD147-positive tumors. Probably, MCT1 cooperates with CD147 in the promotion of a chemoresistance phenotype and possibly, of other functions primarily attributed to CD147. In fact, it appears that CD147 maturation is affected by MCT expression. ${ }^{[102]}$ Other authors have identified CD147 expression in UBC as an independent prognostic biomarker, ${ }^{[103,104]}$ and have additionally proposed it as a predictive biomarker in the setting of cisplatin-containing regimens. ${ }^{[104,105]}$ Recently, one group ${ }^{[106]}$ demonstrated the independent prognostic significance of MCT1 and MCT4 in UBC. Those results led us to knock down CD147 expression in a UBC cell line with a cisplatin-resistant phenotype. We found that CD147 depletion was accompanied by a decrease in MCT1 and MCT4 expressions, additionally supporting its chaperone function. Notably, we also found an increase in chemosensitivity to cisplatin. To the best of our knowledge, this is the first study to assess MCT expression and correlation with CD147 in UBC tissue from platinum-treated patients, and to characterize UBC chemosensitivity to cisplatin in vitro upon CD147 inhibition. Our findings reveal a major role of CD147 and companions in promoting progression of a UBC-aggressive phenotype, with high glycolytic activity, contributing to microenvironmental acidification. This enables the malignant cell to demonstrate growth, migration, invasion, and chemoresistance abilities that can potentially be bypassed if new approaches of targeted therapeutic intervention are investigated. Though investigation of CD147 and its association with metabolic remodeling and chemoresistance is still in a preliminary phase in UBCs, progress has been made in other areas, and CD147-directed monoclonal antibodies have reached the phase of pre-clinical/clinical trials, namely for hepatocellular carcinoma. ${ }^{[107]}$

\section{Concluding Remarks}

Urothelial bladder carcinoma represents about $90 \%$ of all cases of bladder cancer. ${ }^{[5]}$ Its relapsing and progressive nature, and the disparities in treatment responses, are the major concerns in patient care and have a significant socio-economic impact. ${ }^{[10]}$ In an attempt to clarify its heterogeneous natural history and clinical behavior, recent progress has been made in genomic studies. ${ }^{[8,108]}$ This should help in refining our understanding of the pathogenesis of the disease and of the biological basis for outcome disparities. Furthermore, the consequent emergence of UBC biomarkers will allow us to identify patients at increased risk of recurrence, progression, metastasis, and/or chemorefractoryness, informing us about more efficient treatment and surveillance strategies. In addition, biomarkers may improve prediction of response to treatment and guide us to an era of personalized medicine and targeted therapy. In fact, classical diagnostic and prognostic instruments, such as risk stratification tables, ${ }^{[109,110]}$ nomograms, ${ }^{[111,112]}$ and artificial neural networks, ${ }^{[113,114]}$ would undoubtedly refine diagnosis, prognosis, and therapeutic decisions with the inclusion of prognostic and predictive biomarkers. Several studies have demonstrated the potential impact of developing risk stratification tools that combine clinicopathological and biological parameters. ${ }^{[101,115,116]}$ Moreover, it seems that integrating a molecular signature of biomarkers inherent in different cancer hallmarks improves predictive accuracy over one biomarker abnormality, as several biomarkers may help to elucidate individual biological features of tumors. ${ }^{[14,101,117-120]}$ Our previous study on a tumor aggressiveness scoring model, where we combined analysis of 2 clinicopathological parameters, stage and grade, with 3 biological parameters, BVI, LVI, and CD147 overexpression, also corroborates those premises [Table 1]. ${ }^{[101]}$ In fact, the recent genomic profile of UBC revealed a more complex picture than it was previously supposed, with multiple molecular subclasses that traverse conventional grade and stage groupings. ${ }^{[76,121,122]}$ This leads us to believe that only an integrated clinicopathological and molecular signature will refine prognostication and therapeutic index for UBC patients. Therefore, it is important to transpose tests on small groups of patients to large-scale independent validation assays, involving multiple institutions so that prospective validations and randomized trials based on the retrospective outcomes may then proceed. As stated, ${ }^{[123]}$ any newly proposed anticancer strategy must integrate a personalized treatment outcome approach, ideally resulting in a predictive cancer staging system orientated toward the patient and the tumor, and a response evaluation system with multiple standardized variables.

\section{References}

1. Apodaca G. The uroepithelium: not just a passive barrier. Traffic 2004;5:117-28.

2. Ferlay J, Soerjomataram I, Dikshit R, Eser S, Mathers C, Rebelo M, Parkin DM, Forman D, Bray F. Cancer incidence and mortality worldwide: Sources, methods and major patterns in GLOBOCAN 2012. Int J Cancer 2015;136:E359-86.

3. Reuter VE. The pathology of bladder cancer. Urology 2006;67:11-7.

4. Kaufman DS, Shipley WU, Feldman AS. Bladder cancer. Lancet 2009;374:239-49.

5. Burger M, Catto JW, Dalbagni G, Grossman HB, Herr H, Karakiewicz P, Kassouf W, Kiemeney LA, La Vecchia C, Shariat S, Lotan Y. Epidemiology and risk factors of urothelial bladder cancer. Eur Urol 2013;63:234-41. 
6. van Lingen AV, Arends TJ, Witjes JA. Expert review: an update in current and developing intravesical therapies for non-muscle-invasive bladder cancer. Expert Rev Anticancer Ther 2013;13:1257-68.

7. Zagouri F, Peroukidis S, Tzannis K, Kouloulias V, Bamias A, Hellenic Genito-Urinary Cancer Group (HCUCG). Current clinical practice guidelines on chemotherapy and radiotherapy for the treatment of non-metastatic muscle-invasive urothelial cancer: a systematic review and critical evaluation by the Hellenic Genito-Urinary Cancer Group (HGUCG). Crit Rev Oncol Hematol 2015;93:36-49.

8. Knowles MA, Hurst CD. Molecular biology of bladder cancer: new insights into pathogenesis and clinical diversity. Nat Rev Cancer 2014;15:25-41.

9. Cheung G, Sahai A, Billia M, Dasgupta P, Khan MS. Recent advances in the diagnosis and treatment of bladder cancer. BMC Med 2013;11:13.

10. Yeung $\mathrm{C}$, Dinh $\mathrm{T}$, Lee J. The health economics of bladder cancer: an updated review of the published literature. Pharmacoeconomics 2014;32:1093-104.

11. Babjuk M, Burger M, Zigeuner R, Shariat SF, van Rhijn BW, Comperat E, Sylvester RJ, Kaasinen E, Bohle A, Palou Redorta J, Roupret M, European Association of Urology. EAU guidelines on non-muscle-invasive urothelial carcinoma of the bladder: Update 2013. Eur Urol 2013;64:639-53.

12. Witjes JA, Comperat E, Cowan NC, De Santis M, Gakis G, Lebret T, Ribal MJ, Van der Heijden AG, Sherif A, European Association of Urology. EAU guidelines on muscle-invasive and metastatic bladder cancer: summary of the 2013 guidelines. Eur Urol 2014;65:778-92.

13. Birkhahn M, Mitra AP, Williams AJ, Lam G, Ye W, Datar RH, Balic M, Groshen S, Steven KE, Cote RJ. Predicting recurrence and progression of noninvasive papillary bladder cancer at initial presentation based on quantitative gene expression profiles. Eur Urol 2010;57:12-20.

14. van Rhijn BW. Combining molecular and pathologic data to prognosticate non-muscle-invasive bladder cancer. Urol Oncol 2012;30:518-23.

15. Ru Y, Dancik GM, Theodorescu D. Biomarkers for prognosis and treatment selection in advanced bladder cancer patients. Curr Opin Urol 2011;21:420-7.

16. Fuzery AK, Levin J, Chan MM, Chan DW. Translation of proteomic biomarkers into FDA approved cancer diagnostics: issues and challenges. Clin Proteomics 2013;10:13.

17. Ye F, Wang L, Castillo-Martin M, McBride R, Galsky MD, Zhu J, Boffetta P, Zhang DY, Cordon-Cardo C. Biomarkers for bladder cancer management: present and future. Am J Clin Exp Urol 2014;2:1-14.

18. Miremami J, Kyprianou N. The promise of novel molecular markers in bladder cancer. Int J Mol Sci 2014;15:23897-908.

19. Buti S, Ciccarese C, Zanoni D, Santoni M, Modena A, Maines F, Gilli A, Bria E, Brunelli M, Rimanti A, Cascinu S, Ardizzoni A, Tortora G, Massari F. Prognostic and predictive factors in patients treated with chemotherapy for advanced urothelial cancer: where do we stand? Future Oncol 2015;11:107-19.

20. Soloway MS. Bladder cancer: Lack of progress in bladder cancer -what are the obstacles? Nat Rev Urol 2013;10:5-6.

21. Hanahan D, Weinberg RA. Hallmarks of cancer: the next generation. Cell 2011;144:646-74.

22. Mendoza M, Khanna C. Revisiting the seed and soil in cancer metastasis. Int J Biochem Cell Biol 2009;41:1452-62.

23. Leber MF, Efferth T. Molecular principles of cancer invasion and metastasis (review). Int J Oncol 2009;34:881-95.

24. Ferris RL, Lotze MT, Leong SP, Hoon DS, Morton DL.
Lymphatics, lymph nodes and the immune system: barriers and gateways for cancer spread. Clin Exp Metastasis 2012;29:729-36.

25. Pereira ER, Jones D, Jung K, Padera TP. The lymph node microenvironment and its role in the progression of metastatic cancer. Semin Cell Dev Biol 2015;38:98-105.

26. Seyfried TN, Huysentruyt LC. On the origin of cancer metastasis. Crit Rev Oncog 2013;18:43-73.

27. Holopainen T, Bry M, Alitalo K, Saaristo A. Perspectives on lymphangiogenesis and angiogenesis in cancer. J Surg Oncol 2011;103:484-8.

28. Cao Z, Shang B, Zhang G, Miele L, Sarkar FH, Wang Z, Zhou Q. Tumor cell-mediated neovascularization and lymphangiogenesis contrive tumor progression and cancer metastasis. Biochim Biophys Acta 2013;1836:273-86.

29. Shibata MA, Morimoto J, Shibata E, Otsuki Y. Combination therapy with short interfering RNA vectors against VEGF-C and VEGF-A suppresses lymph node and lung metastasis in a mouse immunocompetent mammary cancer model. Cancer Gene Ther 2008;15:776-86.

30. Zhang D, Li B, Shi J, Zhao L, Zhang X, Wang C, Hou S, Qian W, Kou G, Wang H, Guo Y. Suppression of tumor growth and metastasis by simultaneously blocking vascular endothelial growth factor (VEGF)-A and VEGF-C with a receptor-immunoglobulin fusion protein. Cancer Res 2010;70:2495-503.

31. Eklund L, Bry M, Alitalo K. Mouse models for studying angiogenesis and lymphangiogenesis in cancer. Mol Oncol 2013;7:259-82.

32. Gacche RN, Meshram RJ. Angiogenic factors as potential drug target: efficacy and limitations of anti-angiogenic therapy. Biochim Biophys Acta 2014;1846:161-79.

33. Kim S, Ding W, Zhang L, Tian W, Chen S. Clinical response to sunitinib as a multitargeted tyrosine-kinase inhibitor (TKI) in solid cancers: a review of clinical trials. Onco Targets Ther 2014;7:719-28.

34. Welti J, Loges S, Dimmeler S, Carmeliet P. Recent molecular discoveries in angiogenesis and antiangiogenic therapies in cancer. J Clin Invest 2013;123:3190-200.

35. Maione F, Giraudo E. Tumor angiogenesis: methods to analyze tumor vasculature and vessel normalization in mouse models of cancer. Methods Mol Biol 2015;1267:349-65.

36. Pignot G, Bieche I, Vacher S, Guet C, Vieillefond A, Debre B, Lidereau R, Amsellem-Ouazana D. Large-scale real-time reverse transcription-PCR approach of angiogenic pathways in human transitional cell carcinoma of the bladder: identification of VEGFA as a major independent prognostic marker. Eur Urol 2009;56:678-88.

37. Santos L, Costa C, Pereira S, Koch M, Amaro T, Cardoso F, Guimaraes T, Bento MJ, Lobo F, Pinto S, Lopes C. Neovascularisation is a prognostic factor of early recurrence in T1/G2 urothelial bladder tumours. Ann Oncol 2003;14:1419-24.

38. Canoglu A, Gogus C, Beduk Y, Orhan D, Tulunay O, Baltaci S. Microvessel density as a prognostic marker in bladder carcinoma: correlation with tumor grade, stage and prognosis. Int Urol Nephrol 2004;36:401-5.

39. Fauconnet S, Bernardini S, Lascombe I, Boiteux G, Clairotte A, Monnien F, Chabannes E, Bittard H. Expression analysis of VEGF-A and VEGF-B: relationship with clinicopathological parameters in bladder cancer. Oncol Rep 2009;21:1495-504.

40. Afonso J, Santos LL, Longatto-Filho A. Bladder cancer - From basic science to robotic surgery. In: Canda A, editor. Angiogenesis, Lymphangiogenesis and Lymphovascular Invasion: Prognostic Impact for Bladder Cancer Patients. Croatia: INTECH; 2012. p. 87-116. 
41. Ghosh M, Brancato SJ, Agarwal PK, Apolo AB. Targeted therapies in urothelial carcinoma. Curr Opin Oncol 2014;26:305-20.

42. von Hardenberg J, Martini T, Knauer A, Strobel P, Becker A, Herrmann E, Schubert C, Steidler A, Bolenz C. Expression and predictive value of lymph-specific markers in urothelial carcinoma of the bladder. Urol Oncol 2014;32:54.e9-17.

43. Zu X, Tang Z, Li Y, Gao N, Ding J, Qi L. Vascular endothelial growth factor- $\mathrm{C}$ expression in bladder transitional cell cancer and its relationship to lymph node metastasis. BJU Int 2006;98:1090-3.

44. Fernandez-Gomez J, Solsona E, Unda M, Martinez-Pineiro L, Gonzalez M, Hernandez R, Madero R, Ojea A, Pertusa C, Rodriguez-Molina J, Camacho JE, Isorna S, Rabadan M, Astobieta A, Montesinos M, Muntanola P, Gimeno A, Blas M, Martinez-Pineiro JA. Prognostic factors in patients with non-muscle-invasive bladder cancer treated with bacillus Calmette-Guerin: multivariate analysis of data from four randomized CUETO trials. Eur Urol 2008;53:992-1001.

45. Zhou M, He L, Zu X, Zhang H, Zeng H, Qi L. Lymphatic vessel density as a predictor of lymph node metastasis and its relationship with prognosis in urothelial carcinoma of the bladder. BJU Int 2011;107:1930-5.

46. Yang H, Kim C, Kim MJ, Schwendener RA, Alitalo K, Heston W, Kim I, Kim WJ, Koh GY. Soluble vascular endothelial growth factor receptor-3 suppresses lymphangiogenesis and lymphatic metastasis in bladder cancer. Mol Cancer 2011;10:36.

47. Zhang HH, Qi F, Shi YR, Miao JG, Zhou M, He W, Chen MF, Li Y, Zu XB, Qi L. RNA interference-mediated vascular endothelial growth factor-C reduction suppresses malignant progression and enhances mitomycin $\mathrm{C}$ sensitivity of bladder cancer T24 cells. Cancer Biother Radiopharm 2012;27:291-8.

48. Shariat SF, Svatek RS, Tilki D, Skinner E, Karakiewicz PI, Capitanio U, Bastian PJ, Volkmer BG, Kassouf W, Novara G, Fritsche HM, Izawa JI, Ficarra V, Lerner SP, Sagalowsky AI, Schoenberg MP, Kamat AM, Dinney CP, Lotan Y, Marberger MJ, Fradet Y. International validation of the prognostic value of lymphovascular invasion in patients treated with radical cystectomy. BJU Int 2010;105:1402-12.

49. von Rundstedt FC, Mata DA, Groshen S, Stein JP, Skinner DG, Stadler WM, Cote RJ, Kryvenko ON, Godoy G, Lerner SP. Significance of lymphovascular invasion in organ-confined, node-negative urothelial cancer of the bladder: data from the prospective p53-MVAC trial. BJU Int 2014;doi: 10.1111/ bju. 12997.

50. Martin-Doyle W, Leow JJ, Orsola A, Chang SL, Bellmunt J. Improving selection criteria for early cystectomy in high-grade t1 bladder cancer: a meta-analysis of 15,215 patients. J Clin Oncol 2015;33:643-50.

51. Bolenz C, Herrmann E, Bastian PJ, Michel MS, Wulfing C, Tiemann A, Buchner A, Stief CG, Fritsche HM, Burger M, Wieland WF, Hofner T, Haferkamp A, Hohenfellner M, Muller SC, Strobel P, Trojan L. Lymphovascular invasion is an independent predictor of oncological outcomes in patients with lymph node-negative urothelial bladder cancer treated by radical cystectomy: a multicentre validation trial. $B J U$ Int 2010;106:493-9.

52. Algaba F. Lymphovascular invasion as a prognostic tool for advanced bladder cancer. Curr Opin Urol 2006;16:367-71.

53. Mazzucchelli R, Cheng L, Lopez-Beltran A, Scarpelli M, Montironi R. Clinicopathological significance of lymphovascular invasion in urothelial carcinoma. Anal Quant Cytol Histol 2012;34:173-9.

54. Afonso J, Santos LL, Amaro T, Lobo F, Longatto-Filho A.
The aggressiveness of urothelial carcinoma depends to a large extent on lymphovascular invasion --the prognostic contribution of related molecular markers. Histopathology 2009;55:514-24.

55. Chaudhary R, Bromley M, Clarke NW, Betts CD, Barnard RJ, Ryder WD, Kumar S. Prognostic relevance of micro-vessel density in cancer of the urinary bladder. Anticancer Res 1999; 19:3479-84.

56. Shariat SF, Youssef RF, Gupta A, Chade DC, Karakiewicz PI, Isbarn H, Jeldres C, Sagalowsky AI, Ashfaq R, Lotan Y. Association of angiogenesis related markers with bladder cancer outcomes and other molecular markers. J Urol 2010;183:1744-50.

57. Rink M, Cha EK, Green D, Hansen J, Robinson BD, Lotan Y, Sagalowsky AI, Chun FK, Karakiewicz PI, Fisch M, Scherr DS, Shariat SF. Biomolecular predictors of urothelial cancer behavior and treatment outcomes. Curr Urol Rep 2012;13:122-35.

58. Horikawa $\mathrm{Y}$, Kumazawa $\mathrm{T}$, Narita $\mathrm{S}$, Inoue $\mathrm{T}$, Yuasa $\mathrm{T}$, Matsuura S, Nanjo H, Satoh S, Tsuchiya N, Habuchi T. Lymphatic invasion is a prognostic factor for bladder cancer treated with radical cystectomy. Int J Clin Oncol 2007;12:131-6.

59. Ma Y, Hou Y, Liu B, Li X, Yang S, Ma J. Intratumoral lymphatics and lymphatic vessel invasion detected by D2-40 are essential for lymph node metastasis in bladder transitional cell carcinoma. Anat Rec (Hoboken) 2010;293:1847-54.

60. Padera TP, Kadambi A, di Tomaso E, Carreira CM, Brown EB, Boucher Y, Choi NC, Mathisen D, Wain J, Mark EJ, Munn LL, Jain RK. Lymphatic metastasis in the absence of functional intratumor lymphatics. Science 2002;296:1883-6.

61. Padera TP, Stoll BR, Tooredman JB, Capen D, di Tomaso E, Jain RK. Pathology: cancer cells compress intratumour vessels. Nature 2004;427:695.

62. Bolenz C, Auer M, Strobel P, Heinzelbecker J, Schubert C, Trojan L. The lymphatic system in clinically localized urothelial carcinoma of the bladder: morphologic characteristics and predictive value. Urol Oncol 2013;31:1606-14.

63. De Bock K, Cauwenberghs S, Carmeliet P. Vessel abnormalization: Another hallmark of cancer? Molecular mechanisms and therapeutic implications. Curr Opin Genet Dev 2011;21:73-9.

64. Bambury RM, Rosenberg JE. Advanced urothelial carcinoma: overcoming treatment resistance through novel treatment approaches. Front Pharmacol 2013;4:3.

65. Carmeliet P, Jain RK. Molecular mechanisms and clinical applications of angiogenesis. Nature 2011;473:298-307.

66. Videira PA, Piteira AR, Cabral MG, Martins C, Correia M, Severino P, Gouveia H, Carrascal M, Almeida JF, Trindade H, Santos LL. Effects of bevacizumab on autocrine VEGF stimulation in bladder cancer cell lines. Urol Int 2011;86:95-101.

67. Humar R, Kiefer FN, Berns H, Resink TJ, Battegay EJ. Hypoxia enhances vascular cell proliferation and angiogenesis in vitro via rapamycin (mTOR)-dependent signaling. FASEB $J$ 2002; 16:771-80.

68. Watanabe R, Wei L, Huang J. mTOR signaling, function, novel inhibitors, and therapeutic targets. J Nucl Med 2011;52:497-500

69. Fechner G, Classen K, Schmidt D, Hauser S, Muller SC. Rapamycin inhibits in vitro growth and release of angiogenetic factors in human bladder cancer. Urology 2009;73:665-8.

70. Seront E, Rottey S, Sautois B, Kerger J, D'Hondt LA, Verschaeve V, Canon JL, Dopchie C, Vandenbulcke JM, Whenham N, Goeminne JC, Clausse M, Verhoeven D, Glorieux P, Branders S, Dupont P, Schoonjans J, Feron O, 
Machiels JP. Phase II study of everolimus in patients with locally advanced or metastatic transitional cell carcinoma of the urothelial tract: clinical activity, molecular response, and biomarkers. Ann Oncol 2012;23:2663-70.

71. Houede N, Pourquier P. Targeting the genetic alterations of the PI3K-AKT-mTOR pathway: its potential use in the treatment of bladder cancers. Pharmacol Ther 2015;145:1-18.

72. Carneiro BA, Meeks JJ, Kuzel TM, Scaranti M, Abdulkadir SA, Giles FJ. Emerging therapeutic targets in bladder cancer. Cancer Treat Rev 2015;41:170-8.

73. Sun $\mathrm{CH}$, Chang YH, Pan CC. Activation of the PI3K/Akt/ mTOR pathway correlates with tumour progression and reduced survival in patients with urothelial carcinoma of the urinary bladder. Histopathology 2011;58:1054-63.

74. Schultz L, Albadine R, Hicks J, Jadallah S, DeMarzo AM, Chen YB, Nielsen ME, Gonzalgo ML, Sidransky D, Schoenberg M, Netto GJ. Expression status and prognostic significance of mammalian target of rapamycin pathway members in urothelial carcinoma of urinary bladder after cystectomy. Cancer 2010;116:5517-26.

75. Afonso J, Longatto-Filho A, DA Silva VM, Amaro T, Santos LL. Phospho-mTOR in non-tumour and tumour bladder urothelium: pattern of expression and impact on urothelial bladder cancer patients. Oncol Lett 2014;8:1447-454.

76. Cancer Genome Atlas Research Network. Comprehensive molecular characterization of urothelial bladder carcinoma. Nature 2014;507:315-22.

77. Chaffer CL, Weinberg RA. A perspective on cancer cell metastasis. Science 2011;331:1559-64.

78. Hurst DR, Welch DR. Metastasis suppressor genes at the interface between the environment and tumor cell growth. Int Rev Cell Mol Biol 2011;286:107-80.

79. Liu W, Vivian CJ, Brinker AE, Hampton KR, Lianidou E, Welch DR. Microenvironmental Influences on Metastasis Suppressor Expression and Function during a Metastatic Cell's Journey. Cancer Microenviron 2014;7:117-31.

80. Al-Mulla F, Bitar MS, Taqi Z, Yeung K. RKIP: Much more than Raf kinase inhibitory protein. J Cell Physiol 2013;228:1688-702.

81. Yesilkanal AE, Rosner MR. Raf kinase inhibitory protein (RKIP) as a metastasis suppressor: regulation of signaling networks in cancer. Crit Rev Oncog 2014;19:447-54.

82. Escara-Wilke J, Yeung K, Keller ET. Raf kinase inhibitor protein (RKIP) in cancer. Cancer Metastasis Rev 2012;31:615-20.

83. Lamiman K, Keller JM, Mizokami A, Zhang J, Keller ET. Survey of Raf kinase inhibitor protein (RKIP) in multiple cancer types. Crit Rev Oncog 2014;19:455-68.

84. Zaravinos A, Chatziioannou M, Lambrou GI, Boulalas I, Delakas D, Spandidos DA. Implication of RAF and RKIP genes in urinary bladder cancer. Pathol Oncol Res 2011;17:181-90.

85. Afonso J, Longatto-Filho A, Martinho O, Lobo F, Amaro T, Reis RM, Santos LL. Low RKIP expression associates with poor prognosis in bladder cancer patients. Virchows Arch 2013;462:445-53.

86. Bonavida B, Jazirehi A, Vega MI, Huerta-Yepez S, Baritaki S. Roles Each of Snail, Yin Yang 1 and RKIP in the Regulation of Tumor Cells Chemo-immuno-resistance to Apoptosis. For Immunopathol Dis Therap 2013;4:79-92.

87. Bonavida B. RKIP-mediated chemo-immunosensitization of resistant cancer cells via disruption of the NF-kappaB/ Snail/YY1/RKIP resistance-driver loop. Crit Rev Oncog 2014; 19:431-45.

88. Phan LM, Yeung SC, Lee MH. Cancer metabolic reprogramming: Importance, main features, and potentials for precise targeted anti-cancer therapies. Cancer Biol Med 2014;11:1-19.

89. Warburg O. On the origin of cancer cells. Science 1956;123:309-14.

90. Doherty JR, Cleveland JL. Targeting lactate metabolism for cancer therapeutics. J Clin Invest 2013;123:3685-92.

91. Munoz-Pinedo C, El Mjiyad N, Ricci JE. Cancer metabolism: current perspectives and future directions. Cell Death Dis 2012;3:E248.

92. Upadhyay M, Samal J, Kandpal M, Singh OV, Vivekanandan P. The Warburg effect: Insights from the past decade. Pharmacol Ther 2013;137:318-30.

93. Halestrap AP. The SLC16 gene family - Structure, role and regulation in health and disease. Mol Aspects Med 2013;34:337-49.

94. Kirk P, Wilson MC, Heddle C, Brown MH, Barclay AN, Halestrap AP. CD147 is tightly associated with lactate transporters MCT1 and MCT4 and facilitates their cell surface expression. EMBO J 2000;19:3896-904.

95. Xiong L, Edwards CK 3rd, Zhou L. The biological function and clinical utilization of CD147 in human diseases: a review of the current scientific literature. Int $\mathrm{J} \mathrm{Mol} \mathrm{Sci}$ 2014;15:17411-41.

96. Baltazar F, Pinheiro C, Morais-Santos F, Azevedo-Silva J, Queiros O, Preto A, Casal M. Monocarboxylate transporters as targets and mediators in cancer therapy response. Histol Histopathol 2014;29:1511-24.

97. Zhu C, Pan Y, He B, Wang B, Xu Y, Qu L, Bao Q, Tian F, Wang S. Inhibition of CD147 gene expression via RNA interference reduces tumor cell invasion, tumorigenicity and increases chemosensitivity to cisplatin in laryngeal carcinoma Hep2 cells. Oncol Rep 2011;25:425-32.

98. Zeng HZ, Qu YQ, Liang AB, Deng AM, Zhang WJ, Xiu B, Wang H. Expression of CD147 in advanced non-small cell lung cancer correlated with cisplatin-based chemotherapy resistance. Neoplasma 2011;58:449-54.

99. Huang Z, Wang L, Wang Y, Zhuo Y, Li H, Chen J, Chen W. Overexpression of CD147 contributes to the chemoresistance of head and neck squamous cell carcinoma cells. J Oral Pathol Med 2013;42:541-6.

100. Afonso J, Santos LL, Miranda-Goncalves V, Morais A, Amaro T, Longatto-Filho A, Baltazar F. CD147 and MCT1-potential partners in bladder cancer aggressiveness and cisplatin resistance. Mol Carcinog 2014;doi: 10.1002/ mc.22222.

101. Afonso J, Longatto-Filho A, Baltazar F, Sousa N, Costa FE, Morais A, Amaro T, Lopes C, Santos LL. CD147 overexpression allows an accurate discrimination of bladder cancer patients' prognosis. Eur J Surg Oncol 2011;37:811-7.

102. Deora AA, Philp N, Hu J, Bok D, Rodriguez-Boulan E. Mechanisms regulating tissue-specific polarity of monocarboxylate transporters and their chaperone CD147 in kidney and retinal epithelia. Proc Natl Acad Sci USA 2005; 102:16245-50.

103. Xue YJ, Lu Q, Sun ZX. CD147 overexpression is a prognostic factor and a potential therapeutic target in bladder cancer. Med Oncol 2011;28:1363-72.

104. Als AB, Dyrskjot L, von der Maase H, Koed K, Mansilla F, Toldbod HE, Jensen JL, Ulhoi BP, Sengelov L, Jensen KM, Orntoft TF. Emmprin and survivin predict response and survival following cisplatin-containing chemotherapy in patients with advanced bladder cancer. Clin Cancer Res 2007; 13:4407-14.

105. Takata R, Katagiri T, Kanehira M, Tsunoda T, Shuin T, Miki T, Namiki M, Kohri K, Matsushita Y, Fujioka T, Nakamura Y. 
Predicting response to methotrexate, vinblastine, doxorubicin, and cisplatin neoadjuvant chemotherapy for bladder cancers through genome-wide gene expression profiling. Clin Cancer Res 2005;11:2625-36.

106. Choi JW, Kim Y, Lee JH, Kim YS. Prognostic significance of lactate/proton symporters MCT1, MCT4, and their chaperone CD147 expressions in urothelial carcinoma of the bladder. Urology 2014;84:245.e9-15.

107. Tang X, Guo N, Xu L, Gou X, Mi M. CD147/EMMPRIN: an effective therapeutic target for hepatocellular carcinoma. J Drug Target 2013;21:224-31.

108. Choi W, Czerniak B, Ochoa A, Su X, Siefker-Radtke A, Dinney C, McConkey DJ. Intrinsic basal and luminal subtypes of muscle-invasive bladder cancer. Nat Rev Urol 2014; $11: 400-10$

109. Sylvester RJ, van der Meijden AP, Oosterlinck W, Witjes JA, Bouffioux C, Denis L, Newling DW, Kurth K. Predicting recurrence and progression in individual patients with stage Ta T1 bladder cancer using EORTC risk tables: a combined analysis of 2596 patients from seven EORTC trials. Eur Urol 2006;49:466-5.

110. Fernandez-Gomez J, Madero R, Solsona E, Unda M, Martinez-Pineiro L, Gonzalez M, Portillo J, Ojea A, Pertusa C, Rodriguez-Molina J, Camacho JE, Rabadan M, Astobieta A, Montesinos M, Isorna S, Muntanola P, Gimeno A, Blas M, Martinez-Pineiro JA. Predicting nonmuscle invasive bladder cancer recurrence and progression in patients treated with bacillus Calmette-Guerin: The CUETO scoring model. J Urol 2009;182:2195-203.

111. Karakiewicz PI, Shariat SF, Palapattu GS, Gilad AE, Lotan Y, Rogers CG, Vazina A, Gupta A, Bastian PJ, Perrotte P, Sagalowsky AI, Schoenberg M, Lerner SP. Nomogram for predicting disease recurrence after radical cystectomy for transitional cell carcinoma of the bladder. $J$ Urol 2006;176:1354-61.

112. Shariat SF, Karakiewicz PI, Palapattu GS, Amiel GE, Lotan Y, Rogers CG, Vazina A, Bastian PJ, Gupta A, Sagalowsky AI, Schoenberg M, Lerner SP. Nomograms provide improved accuracy for predicting survival after radical cystectomy. Clin Cancer Res 2006;12:6663-76.

113. Bassi P, Sacco E, De Marco V, Aragona M, Volpe A. Prognostic accuracy of an artificial neural network in patients undergoing radical cystectomy for bladder cancer: a comparison with logistic regression analysis. BJU Int 2007;99:1007-12.

114. Buchner A, May M, Burger M, Bolenz C, Herrmann E, Fritsche HM, Ellinger J, Hofner T, Nuhn P, Gratzke C, Brookman-May S, Melchior S, Peter J, Moritz R, Tilki D, Gilfrich C, Roigas J, Zacharias M, Hohenfellner M, Haferkamp A, Trojan L, Wieland WF, Muller SC, Stief CG, Bastian PJ. Prediction of outcome in patients with urothelial carcinoma of the bladder following radical cystectomy using artificial neural networks. Eur J Surg Oncol 2013;39:372-9.

115. Shariat SF, Margulis V, Lotan Y, Montorsi F, Karakiewicz PI. Nomograms for bladder cancer. Eur Urol 2008;54:41-53.

116. Shariat SF, Karakiewicz PI, Godoy G, Lerner SP. Use of nomograms for predictions of outcome in patients with advanced bladder cancer. Ther Adv Urol 2009;1:13-26.

117. Shariat SF, Karakiewicz PI, Ashfaq R, Lerner SP, Palapattu GS, Cote RJ, Sagalowsky AI, Lotan Y. Multiple biomarkers improve prediction of bladder cancer recurrence and mortality in patients undergoing cystectomy. Cancer 2008;112:315-25.

118. Bryan RT, Zeegers MP, James ND, Wallace DM, Cheng KK. Biomarkers in bladder cancer. BJU Int 2010;105:608-13.

119. Shariat SF, Chade DC, Karakiewicz PI, Ashfaq R, Isbarn H, Fradet Y, Bastian PJ, Nielsen ME, Capitanio U, Jeldres C, Montorsi F, Lerner SP, Sagalowsky AI, Cote RJ, Lotan Y. Combination of multiple molecular markers can improve prognostication in patients with locally advanced and lymph node positive bladder cancer. $J$ Urol 2010;183:68-75.

120. Lotan Y, Bagrodia A, Passoni N, Rachakonda V, Kapur P, Arriaga Y, Bolenz C, Margulis V, Raj GV, Sagalowsky AI, Shariat SF. Prospective Evaluation of a Molecular Marker Panel for Prediction of Recurrence and Cancer-specific Survival After Radical Cystectomy. Eur Urol 2013;64:465-71.

121. Damrauer JS, Hoadley KA, Chism DD, Fan C, Tiganelli CJ, Wobker SE, Yeh JJ, Milowsky MI, Iyer G, Parker JS, Kim WY. Intrinsic subtypes of high-grade bladder cancer reflect the hallmarks of breast cancer biology. Proc Natl Acad Sci U S A 2014;111:3110-5.

122. Choi W, Porten S, Kim S, Willis D, Plimack ER, Hoffman-Censits J, Roth B, Cheng T, Tran M, Lee IL, Melquist J, Bondaruk J, Majewski T, Zhang S, Pretzsch S, Baggerly K, Siefker-Radtke A, Czerniak B, Dinney CP, McConkey DJ. Identification of distinct basal and luminal subtypes of muscle-invasive bladder cancer with different sensitivities to frontline chemotherapy. Cancer Cell 2014;25:152-65.

123. Brücher BL, Lyman G, van Hillegersberg R, Pollock RE, Lordick F, Yang HK, Ushijima T, Yeoh KG, Skricka T, Polkowski W, Wallner G, Verwaal V, Garofalo A, D’Ugo D, Roviello F, Steinau HU, Wallace TJ, Daumer M, Maihle N, Reid TJ 3rd, Ducreux M, Kitagawa Y, Knuth A, Zilberstein B, Steele SR, Jamall IS. Imagine a world without cancer. BMC Cancer 2014;14:186.

How to cite this article: Afonso JP, Freitas R, Lobo F, Morais A, Oliveira J, Amaro T, Reis RM, Baltazar FM, Longatto-Filho A, Santos LL. Urothelial bladder cancer progression: lessons learned from the bench. J Cancer Metastasis Treat 2015;1:57-66.

Received: 18-02-2015; Accepted: 05-05-2015. Source of Support: Nil, Conflict of Interest: None declared. 